University of Windsor

Scholarship at UWindsor

OSSA Conference Archive

OSSA 3

May 15th, 9:00 AM - May 17th, 5:00 PM

\title{
A Theory of Normative Reasoning Schemes
}

J Anthony Blair

University of Windsor

Follow this and additional works at: https://scholar.uwindsor.ca/ossaarchive

Part of the Philosophy Commons

Blair, J Anthony, "A Theory of Normative Reasoning Schemes" (1999). OSSA Conference Archive. 3. https://scholar.uwindsor.ca/ossaarchive/OSSA3/papersandcommentaries/3

This Paper is brought to you for free and open access by the Conferences and Conference Proceedings at Scholarship at UWindsor. It has been accepted for inclusion in OSSA Conference Archive by an authorized conference organizer of Scholarship at UWindsor. For more information, please contact scholarship@uwindsor.ca. 
Title: A Theory of Normative Reasoning Schemes

Author: J. Anthony Blair

Response to this paper by: James Freeman

(c)2000 J. Anthony Blair

\section{INTRODUCTION}

This is an essay on what Michael Scriven termed "probative logic" in a keynote address at the first ISSA conference in Amsterdam thirteen years ago. Probative logic is, for Scriven, the logic of probative inference, and these are inferences "of a kind that is neither deductive nor quantitatively probabilistic, but, thoughtful people normally believe, properly thought of as strongly persuasive to the rational faculty" (1987: 9). One is reminded of J.S. Mill's characterization, in Chapter 1 of Utilitarianism, of his proof of the principle of utility, which, he said "cannot be proof in the ordinary and popular meaning of the term." Instead, what he proposed to provide are, "Considerations ... capable of determining the intellect either to give or withhold its assent to the doctrine;" and, Mill added: "this is equivalent to proof" (Mill 1861: 4-5). [William $\mathrm{K}$. Frankena, in lectures, noted the significance of this passage in Utilitarianism.]

This topic is central to informal logic-one might even say definitive of it. That there are good arguments which use reasoning that is neither deductive nor scientifically inductive has been a guiding conviction of many who work in this field. It underlies the search for other criteria of good arguments that produced the Acceptability, Relevance and Sufficiency criteria Johnson and Blair introduced (1977). Trudy Govier recognized its significance when she drew attention to conductive inference and case-by-case reasoning in the early 1980s (1980a, 1980b, 1987). Much more recently, Douglas Walton, is taking up this topic under a different name in his study of presumptive reasoning (1996). There are probably many others who should be mentioned, but the reference to Govier's and Walton's work will provide a sense for the project of the present essay.

The paper is divided into two parts. Section 2 introduces a number of terminological conventions, and explains what motivates the paper. Section 3 contains the main business of the paper: the analysis of the concept of a reasoning scheme and the sketch of a theory of normative reasoning schemes

\section{PRELIMINARIES}

\subsection{Terminology}

\subsection{1 'Reasons'}

It will avoid some possible confusion to talk about "reasons" instead of "premises" or "arguments." A reason is here taken to be a unit of support for a position, taking a "position" to be an attitude towards a proposition, 
understanding 'proposition' broadly, to include action or policy recommendations or evaluations as well as what is expressed by (strictly true or false) declarative sentences. For example, with respect to the proposition, $<$ The Lewinsky affair weakened the American presidency> any number of positions is possible: "The Lewinsky affair weakened the American presidency," "The Lewinsky affair probably weakened the American presidency," "It is doubtful that the Lewinsky affair weakened the American presidency," "It is a shame that the Lewinsky affair weakened the American presidency," and so on. (The chevrons "<>" bracket a proposition that is mentioned but not asserted; the quotation marks bracket an assertion or possible assertion). A person's reason for a position is a consideration that the person takes to support it. A person's reason is a proposition, or a set of propositions, that the person takes to be true (or otherwise acceptable) and to lend support to a position. [While I'm not sure that Freeman (1991) would agree entirely with my stipulation, he does seem to me to use 'reason' in a similar if not identical way (see, for example, p. 94 and p. 96).]

A reason may support (or be purported to support) a position, by doing (or being purported to do) any of the following: demonstrate or prove the position (that is, establish that it must be true); show that the position is probable to some degree; or show that the position is plausible to some degree (that there is a presumption of some degree in its favour).

A person may have more than one reason for a position. In the case of reasons that logically entail positions (in the sense that, if the reason is true the position cannot be false), more than one would be redundant; but people can and do have redundant support for positions. In the case of reasons that constitute empirical evidence or that supply presumptive support, it is often appropriate to have more than one reason for a position, since in that case more reasons can mean stronger support.

Still, a single reason provides at least some measure of support for a position. A "single" reason may include more than one proposition. What is the difference between a single, multi-propositional reason and two or more reasons? A single reason is the smallest amount of information that by itself lends some measure of credence to a position.

Here are some examples of possible reasons supporting positions:

(1) S's reason: The rules prevent the game from ending in a draw.

S's position: If the game ends, one side in the game must lose.

(2) S's reason: 90 of the 100 balls in the urn are black, ten are white, and the balls in the urn have been thoroughly mixed.

S's position: If anyone reaches into the urn and without looking takes out a ball, it is highly probable that this ball will be black, not white. 
(3) S's reason: Sheila told Ed she would treat him to dinner.

S's position: Sheila should treat Ed to dinner.

(4) S's reason: If the city council gives special recognition of a "day" for Immigrants from lceland, it will have to do the same for virtually any group that applies, and it is likely that hundreds of other groups would then apply. The result would be a special recognition "day" every day, and even special recognition "days" shared by more than one group, which would defeat the purpose of special recognition.

S's position: The city council shouldn't give special recognition of a "day" for Immigrants From Iceland.

\subsection{2 'Argument' and 'reasoning'}

In the informal logic and argumentation literature the terms 'argument' and 'reason' (and their cognates) are used loosely. Walton is a typical example. He titles the book discussed in this paper, "Argumentation Schemes for Presumptive Reasoning"(1996), suggesting a connection, and throughout that book he slips back and forth between referring to "argumentation" schemes and "reasoning" schemes, as if argumentation and reasoning were identical. Clearly, they are not (and to be fair, Walton does not claim they are, though he does not address their connection). Scriven is another example: he calls one of his books Reasoning (1976), and the book is about analyzing and evaluating arguments. Yet another is Feldman, whose textbook, Reasons and Argument, begins with the sentence, "This book presents a method for understanding and evaluating arguments" (1999: 1). Or again, see Groarke, Tindale and Fisher, who write in their introduction to Good Reasoning Matters!: "This book is designed to help you [the student] to improve your reasoning skills. ... It is our hope that you will become proficient not only at assessing the arguments you encounter, but also at constructing arguments of your own" (1997: xiii-xiv). For these authors, none of whom address the connection, the relation between reasoning and argument is close and unproblematic. However, reasoning is not arguing; moreover there are at least two significantly different senses of 'argument' in play in these works. [For those familiar with it, I am not here referring to Daniel O'Keefe's classical distinction between argument ${ }_{1}$ and argument $_{2}$; rather, I am making a distinction between two senses of argument ${ }_{1}$ (see O'Keefe, 1977, 1982).]

When a person reasons, she infers or draws inferences. She may, like Harman's "Mary" (1986: 1), change her view in the process, but not necessarily, for she may, by reasoning, confirm an already-held view. In either case she draws a conclusion, that is, takes (or reaffirms) a position, on the basis of certain grounds that she accepts and takes to support it. The set of reasons that in her judgement supports a position is, in philosophical literature, standardly called her "argument" for the position, although she has not argued at all. Thus, for example, if Mary reasons that since she is out of eggs and 
plans to make a soufflé tonight, she should buy eggs today, philosophers will describe her reasoning as consisting of the following "argument": "Premise 1: 'I am out of eggs'; Premise 2: 'I plan to make a soufflé tonight'; Premises 3 and 4 (unexpressed): 'Eggs are needed to make a soufflé and the best way for me to get eggs is to buy them'; Conclusion: 'I should buy eggs today.'" Let us call this the Philosophers' (or the Propositional) sense of argument, or a Pargument, and emphasize that its use does not entail the occurrence of any action or activity that could be called arguing. One has to imagine eccentric scenarios to come up with a context in which Mary, in her circumstances, might argue that she should buy eggs today. When Mary proposes reasons to others as grounds that support a position, inviting them to accept it on those grounds or trying to persuade or convince them to accept it on those grounds, then she is engaged in the activity of arguing (see Pinto 1995). In order to argue, one must communicate with others. Let us call the grounds that Mary proposes to others for accepting a position her Speech-act argument, or an SA-argument. Notice that Mary's SA-argument for a position might be different from her Pargument for it. The reasons she offers to others might or might not be her reasons, but they will be reasons she thinks others will embrace as their ownreasons they will take to support the position she is putting forward. In what follows I will use 'argument' exclusively to denote SA-arguments, and 'reasons' or 'reasoning' to denote P-arguments.

Thus an argument (an SA-argument) consists of one or more reasons for endorsing a position offered by an arguer normally to one or more other people (an "audience"), but sometimes also to herself. The word 'endorsing' is a place-holder for any of a variety of specifics, including believing, assuming, accepting, recommending, and acting on; and, as indicated above, the word 'position' is the placeholder for any point of view taken towards a proposition, understanding 'proposition' broadly. So a position may be: that a proposition is true or plausible or probable, and so on; or that an action should be taken, a policy pursued or endorsed, and so on; or that an attitude is appropriate or justified, and so on.

I think van Eemeren and Grootendorst are right to extend the Searlean concept of an assertive beyond the expression of commitment to the truth or falsity of a proposition to include, more broadly, the expression of any attitude of positive or negative commitment towards a sentence, understanding sentence to embrace not only factual sentences that are true or false, but also normative sentences whose truth-value status may be problematic (1984: 9596). It might be fruitful to extend the concept of a proposition along similar lines, and I use the word 'proposition' in such an extended way in this paper. (They use the word 'statement' where I have written 'sentence,' but I take 'statement' to denote an asserted proposition, which is just what is at issue.) This view has implications for Walton's analysis of the speech act of presumption, discussed below.

As the word is used here, an argument is always someone's argument, just as a reason is someone's reason. Sets of propositions that might serve as 
reasons for endorsing a claim but that no one has proposed or accepted as such are, in my terminology, only possible arguments. Thus the reasons offered in arguments are asserted propositions, or "statements." There is not a parallel terminology for propositions that have been accepted or believed in reasoning, but not expressed, but we might call them endorsed or assented-to propositions. This is not the way Harman and others use 'argument,' to denote exclusively a proof or implication relation (1986: 3-4), although proofs can be used as, or found in, arguments.

An argument can consist of more than one reason for accepting the position. Why should someone ever offer more than one reason to support a position? Here are some reasons:

The arguer believes that the reason provides only weak support for the position, and that the audience will agree, and he wishes to supply additional support so that the total support provided by all the reasons he offers adds up to strong support for the position.

The arguer believes the audience might not accept the reason and he wishes to supply another one as an alternative reason that the audience may use if it does not accept the first one.

The arguer believes the audience might not accept some part of the reason and he wishes to supply a supplementary reason to persuade the audience to accept that part of the initial reason.

The arguer believes that although the audience might accept his reason, it might also believe there is at least one detracting or refuting reason that overrides his, and he wishes to supply a reason why the audience should discount or reject the detracting or refuting reasons, or else should reject its status as overriding the initial reason.

\subsection{Assumptions}

It is widely held that not all arguments are intended to be, nor (even with premises added) are they plausibly reconstructed as, deductive or valid arguments, that is, arguments in which the premises entail the conclusion in the sense that it is impossible for the premises to be true and the conclusion false (although that view is not universally endorsed: see Groarke 1999).1But it is not so widely held that all arguments are either deductive or inductive.2However, Govier has made a decisive case against the exhaustiveness of that dichotomy.

Govier points out that if 'inductive' is defined as "non-deductive," "[t]oo many different types of argument will fall into the class, the result being that saying an argument is in the broad sense inductive tells us essentially nothing about it. It says only what the argument is not—not what it is" (1999, Ch. 10). If induction is associated with empirical or scientific reasoning, as it has been, then, Govier points out, even within that category there are several quite 
different types of reasoning that need to be distinguished: inductive analogy, inductive generalization (enumerative induction), non-disconfirmation, experimental data to causal hypothesis, and abductive reasoning (ibid.). And quite apart from failing to distinguish types of reasoning or argument used in empirical or scientific thinking, this dichotomy leaves out both a priori analogical reasoning or arguments and also conductive reasoning or arguments, each of which Govier persuasively defends as sui generis, and not reducible to deductive reasoning or arguments (see 1999, Ch. 9 and Ch. 10, respectively).

Govier is not alone in holding that the categories of deductive and inductive reasoning or argument are not exhaustive. We have seen that Scriven and Walton would agree. In his discussion of presumptive reasoning, after reviewing some examples of reasoning offered by Reiter (1987), Walton notes: "The conclusion to be drawn from these cases then is that the understanding of nonmonotonic reasoning is not to be sought in deductive or inductive formal systems of inference, but in a more broadly pragmatic account ..." (1996: 23). Walton's Argument Schemes for Presumptive Reasoning is devoted to the analysis of a number of patterns of inference or argument that fall outside the deductive-inductive dichotomy (see Walton 1996: passim).

\subsection{Motivation}

What motivates the present paper is a question that arises on the assumption that Scriven, Govier, Walton and others who share their position here are right. That question is simply this: What grounds such reasoning or arguments? When the reasons don't entail the position, or provide strong quantitative inductive support for it, then how is one to be justified in accepting it? What makes for "valid" or cogent reasoning or arguments belonging to this Third Category? (By the way, we should not assume that this Third Category is homogeneous. It may well be that there are major differences between types of reasoning and arguments that are neither deductive nor inductive.)

A way to see the gist of this question is to contrast deductive and inductive reasoning and arguments with those of this Third Category. When the reasons deployed in an episode of reasoning or in an argument entail the position, we can see that on the assumption of those reasons it is rational to accept the position because otherwise we face self-contradiction. The norm of strict, logical consistency justifies reasoning and arguments of this sort. When an accepted body of evidence provides strong inductive support for an empirical position then, in very general terms, there is an analogous constraint of consistency on our reasoning. A world in which the many and varied evidential propositions that supply inductive support for an empirical position are true (including the premise that conflicting evidence or hypotheses are unlikely), yet the position is false, is a world in which (some of) our current empirical beliefs or theories are incorrect. It is not an impossible world, but it is either 
implausible or else less plausible than the world as we nowknow it. In that sense, accepting the conclusion of such reasoning or such an argument is being consistent with our other beliefs, and rejecting it is being inconsistent with them. To be sure, the situation in particular instances of "inductive reasoning" or "inductive argument" is more complex, but the assumption is that as a general picture this account is roughly right. Now, the question being posed here may be put this way. Is there some analogous kind of inconsistency in accepting the reasons but rejecting the position allegedly supported by them in reasoning or arguments belonging to the Third Category? If so, what is it, and if not, then on what grounds is it rational to accept the positions in Third Category reasoning or arguments? Anyone who agrees that there are legitimate kinds of reasoning and argument that are not, directly or indirectly, deductive or inductive, faces this question.

\subsection{Link to reasoning/argument schemes}

In Argumentation Schemes for Presumptive Reasoning (1996), Walton examines what he calls schemes for presumptive arguments or reasoning, which he takes to be "normatively binding" in the sense that:

If the hearer accepts the premises of the speaker's argument, and the argument is an instance of a genuine and appropriate argument scheme (for the type of dialogue they are engaged in), then the hearer must or should (in some binding way) accept the conclusion. This does not appear to be "validity" in the same sense in which the word is familiarly used in deductive (or perhaps even inductive) logic. But it does appear to express a normative or broadly logical sense of validity, bindingness, conditional acceptability, or whatever you want to call it. (10)

Clearly Walton is here on the track of an answer to the question of this essay. If we can get an understanding of what is a "genuine and appropriate" argument scheme and of how such schemes constrain or bind their hearers (or users) to accept their conclusions-having accepted their premises-then we have the answer (or one answer) to our question. Thus it is that the question motivating this inquiry leads to an examination of reasoning schemes.

\section{REASONING SCHEMES}

To start, we need to decide whether we should be speaking of reasoning (or inference) schemes, or of argument (or argumentation) schemes. Kienpointner (1991) refers to them as argumentation schemata. 3 Walton (1996) switches back and forth between calling them argument (also argumentation) schemes and inference schemes (or schemes for reasoning). Van Eemeren and Grootendorst call them argumentation schemes. Following the terminological conventions introduced above, the schemes are reasoning schemes, for they are representations of reasons, whether those reasons function in a person's own reasoning (inferences), or whether they are used in 
an argument that the person presents to an audience.

[Perhaps another clarification is needed. What is the difference between argumentation and argument? These terms are widely used interchangably, but also differently. Notice that Kienpointner uses the German word 'Argument,' where English-speaking philosophers might use the words 'premise,' 'reason' or evidence.' Walton writes of listing "argumentation" schemes (e.g.: "In this chapter, 25 different argumentation schemes are described and analyzed" (46)), but he labels the schemes "argument from" this or that: "Argument from Sign," "Argument from Example," and so on. At one point, he writes, "Hastings (1963) identified argument from sign as a distinctive argumentation scheme ..." (47). Perhaps Walton is conceiving arguments as units or components of argumentation, but there seems to be no consistent usage. Consequently, we may conclude that the occurrences of 'argument' and 'argumentation' in the literature indicate no settled and widely-accepted technical conventions distinguishing their meanings, although I don't claim that no author differentiates them systematically.]

\subsection{What is a reasoning scheme?}

What is a reasoning scheme? It seems that everyone is expected to know already, for although examples abound in the literature, clearcut analyses of the concept are hard to come by. Walton (1996), Kienpointner (1992) and van Eemeren and Grootendorst (1992) each draws attention to what is either a slightly different conception or to a different property of reasoning schemes. However, from the three accounts, a single comprehensive conception can be constructed.

\subsubsection{Three general accounts of reasoning schemes}

Walton quotes Hastings as calling argument schemes "modes of reasoning" (1996: ix), and goes on to describe an "argumentation" scheme as "a structure of inference" (ibid.). He says that argumentation schemes are "certain common forms of argument" (ibid.: 1) and more precisely are "a formal, pragmatic structure of arguments that is the counterpart to logical forms of inference in semantics" (ibid.: $\mathrm{x}$ ).

Kienpointner (1992) says that by making a broad abstraction, all simple normative or descriptive arguments can be reduced to a context-independent basic scheme, which is a "prototype" in terms of which the context-specific argumentation schemes of every argumentation can be distinguished (ibid., 19: "Schliesslich Könen durch wietere Abstraktionsshchritte alle einfachen normativen oder deskriptiven Argumentationen auf ein kontextunabhäniges Grundschema reduziert werden, das als ,Prototype" aller mehr oder weniger kontextspezifischen Alrgumentationsshemata der Alltagsargumentation angehsehen werden kann:") That prototype is: 


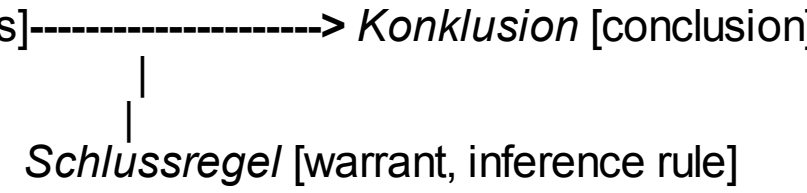

(Kienpointner acknowledges that he has borrowed the Toulmin model of argument.)

Van Eemeren and Grootendorst say an argumentation scheme is "a more or less conventionalized way of representing the relation between what is stated in the argument [the "reason"] and what is stated in the standpoint [the "position"]" (1992: 96).

Both Walton and van Eemeren and Grootendorst emphasize that associated with any reasoning scheme is a set of "critical questions." These are questions that must be answered appropriately if any substitution instance of a reasoning scheme is to be cogent. On neither account, though, is the motivation of the questions associated with reasoning scheme given a general explanation.

What all these authors clearly have in mind is some general pattern of argument or reasoning that has either been abstracted from particular cases or can find instantiation in different particular cases, or both. In the terminology of this essay, it is the pattern of the reason taken to support a position. It is an abstract representation of an actual or a possible reason. What makes a scheme an "abstraction" is that particular terms or phrases or propositions in the statement of an actual reason are expressed by variables in the scheme's statement of it. What makes such a scheme normative is that there is some justification for reasoning along its lines.

\subsubsection{One example: inferring from someone's sayso}

All of this is suggestive, but it skirts the heart of the matter. In order to bring out the essential nature of a reasoning scheme, it is instructive to use an example as illustrative. Consider the reasoning involved in an appeal to some source of information as the reason for accepting a position. The "appeal to authority" and the "appeal to expert opinion" are variants of this reasoning. One way to characterize this reasoning scheme is as follows, where ' $S$ ' represents a person or persons (not always identified, as when ' $S$ ' denotes the authors of a dictionary entry) and where ' $P$ ' represents a position:

The "Appeal to a Source" reasoning scheme

$S$ asserts $P$.

Normally, when $S$ asserts $P, P$. 
Can such reasoning ever be any good-or, more precisely, can substitution instances of this reasoning scheme ever be any good? Certainly. Without exaggeration, billions of examples of good reasoning that exhibits this pattern are available. One will suffice.You ask your partner what time it is, and he/she tells you that it's around nine o'clock. His or her telling you that it is around nine o'clock in answer to your question is an excellent reason to believe that it is indeed around nine o'clock, other things being equal. Thus your reasoning, "It is probably around nine o' clock because my partner tells me it is around nine o'clock (and there is no reason to doubt him)" is excellent reasoning.

A more interesting question than whether this reasoning is any good is the question why it is reasonable for a reasoner $R$ to believe $P$ in circumstances $C$ because $S$ says it is so. The answer seems to run along the following lines. It is reasonable for $R$ to believe $P$ on $S$ 's sayso in $C$ just to the extent that there exists in $C$ a practice of truthfulness, at least between $R$ and $S$. In many societies there is a fairly widely practiced convention that you don't assert a proposition (that is, express it in a way that represents it as true), without qualification, unless you believe it to be true and think you have good grounds for your belief. It is that convention, insofar as $R$ is justified in believing that it applies to $R$ and $S$ in $C$, that makes it reasonable for $R$ to accept $P$ if $S$ asserts that $P$, other things being equal. It is against that background that someone's saying that $P$ is generally a good reason for accepting $P$.

To be sure, like any social practice, truthfulness is complicated. For instance, we make distinctions between fact and fiction: not all cases of saying that $P$ are cases of asserting that $P$. We also distinguish between facts (as in observation reports) and opinions (as in judgement calls) Moreover, we recognize that while such contrast pairs are useful, they are idealizations. We teach our children the difference between inventions or "stories" and descriptions or facts, and we wait until they are older to introduce them to the unclear borderline cases, for example such questions as whether Farley Mowat's fictionalized account of the Barren-Land Inuit was in some sense true, or whether a baseball umpire's call expresses a description or a judgement. (On the former, see Mowat's People of the Deer. The book was taken at the time to be a record of an historical event, the starvation of the Barren-Land Innuit in northern Canada in the winter of 1948, but details of its narrative were later shown to contain significant invention.) In addition, we understand that there are special contexts in which truth-telling is highly qualified, as in certain kinds of commercial marketplace bargaining, or in diplomatic exchanges (affairs of state). And so on.

There are two related reasons for a ceteris paribus qualification in the "Appeal to a Source" reasoning scheme. First, $S$ 's telling $R$ that $P$ is, in some conditions, not a good reason for $R$ to accept $P$, and second, it is impossible to specify in any useful way (if at all) all those conditions. In general, there is an exception to the scheme in circumstances when $S$ might not be following the 
truth-telling convention, or when $S$ might be wrong about $P$.

Notice that it is impossible to specify all the types of circumstances in which these exceptions occur. There is an indefinite number of kinds of situation in which a person might be less than truthful, or might be innocently mistaken. So there can be no algorithm for good "Appeal to a Source" reasoning.

Neverthless, since, in spite of its capacity for infinite variation, human conduct and motivation tend to follow a limited number of well-defined paths, it is possible to outline in a general way for any scheme the principal classes of exceptions to it, and so to provide useful general, if not universal, guidelines for the employment of that scheme. And that is the role of the so-called "critical questions" associated with each reasoning scheme. They remind us of types of circumstances that derail reasoning of the pattern represented by the scheme. As Walton (1996) points out, the ceteris paribus feature of reasoning schemes has the effect of placing reasoning according to them in the role of the "default" in circumstances in which reasoning in that way is appropriate. The critical questions function as a check-list to help determine whether any of the standard types of excepting conditions that should cancel the default is present in the given case.

This last point can be illustrated using our example of the "Appeal to a Source" scheme, as the following paragraphs illustrate in some detail.

One general type of reason for cancelling the default in such reasoning is that there are grounds for thinking that $S$ might not be following the truth-telling convention in the given case. That possibility motives the general critical question, "Is there any reason not to trust $S$ to be truthful on this occasion?" And if it is useful to specify some of the circumstances that would justify questioning $S$ 's truthfulness, then more particular critical questions can be formulated, for example: "Does $S$ have any interest in not being truthful in this case?" And conditions for such special circumstances can also be checked, for example: "Will S gain monetarily by asserting $P$ in this case although he does not believe $P$ is true?"

Another general type of reason for cancelling the default in " $P$ is true because $S$ says so"-reasoning is that there are grounds for thinking that $S$ might be wrong about $P$ in this case. That possibility motivates the general critical question, "Is $S$ in a position to know that $P$ on this occasion?" And as with the previous general critical question, this one can also spawn more particular questions that delve into ways in which $S$ might fail to be in a position to know that $P$ on this occasion, such as, "Does $S$ have the requisite qualifications to know whether $P$ is true?" and "Has $S$ investigated whether $P$ is true?"

Moreover, we can distinguish different types of $S$ and $P$, according to whether there is some reason to assign some of them a special status. In our culture we have the role of "expert" and the status of "specialized knowledge." Specialized knowledge is information that is not capable of being known or 
understood by anyone lacking expertise, and an expert is someone who has the training and knowledge required to understand these otherwise inaccessible matters. We assign epistemic privilege or authority to the expert in matters of specialized knowledge within her perview. So if $P$ belongs to a specialized knowledge field $(F)$, then "S says that $P$ " is a reason to believe $P$ only if $S$ is an expert in $F$, ceteris paribus. Accordingly, we can formulate specialized critical questions to check whether a given $P$ falls within a domain of specialized knowledge, and if so whether a given $S$ is an expert with respect to that field. As fields of specialized knowledge have become more complex and specializations of necessity have become narrower, we have altered our critical questions to check for such factors: for example, "Is $S$ an expert not only in $F$ in general, but more particularly in $F$, the part of $F$ to which $S$ belongs?" We also recognize that expertise or epistemic authority comes in degrees: we assign greater authority about cancer diagnoses to oncologists than to family medicine physicians, for example.

We know that experts no less than others can violate the trust put in them, and can claim to know things that they have no better access to than anyone else (as when physicians give advice in moral matters, for example) or claim certainty when there are grounds for doubt (as when a physician presents a diagnosis to the patient categorically, when she should know that it is controversial and so her diagnosis should be qualified). Accordingly, we formulate additional critical questions to check out such possibilities, to see whether an expert appealed to undermines her authority in these ways, thus weaking the support of " $S$ says that $P$ " for $P$ in $F$.

We do not surrender our epistemic authority to experts completely. If an expert makes a pronouncement, $P$, that strikes us as goofy (utterly implausible), we are inclined to reject $P$, no matter what the expert's qualifications. If your dentist tells you he sees tiny people cavorting among your molars, you don't ask for a mirror so you can see them too. So we formulate critical questions to remind ourselves to check the plausibility of $P$ independently of any credibility it receives by virtue of $S$ 's having asserted it in $C$. Moreover, nothing in principle prevents the plausibility of the position in question from conflicting with the credibility of the source who asserts it, requiring a balance-of-considerations judgement about the relative acceptability of $P$.

As noted above, we can't make perfect lists of critical questions, because situations differ in unpredictable ways (so no exhaustive list of all the possibilities is possible), but also because different situations may call up factors that don't apply universally. If $P$ is accessible only to those with advanced scientific training (e.g., "Will the weight of the new engines increase metal fatigue dangerously?"), then $S$ has to have properties that pertain-have the advanced scientific training, have done or studied the research bearing on $P$, and so on. But if $P$ is accessible only to those with personal experience (e.g., "What's it like to give birth?"), then $S$ has to have had personal 
experience of $P$, which may require no training whatever. Disagreements among experts will raise questions about some $P$ s, as when physicians consulted for a diagnosis of a set of symptoms disagree. But in other cases, disagreements among those who are knowledgable is irrelevant, as when movie critics disagree about whether a certain movie is good, but the particular critic whose taste and values you have found invariably to coincide with your own makes an unequivocal thumbs up or thumbs down judgement.

Another reason we can't make perfect lists is that the degree to which a condition is met or not met can be signficant. So, perhaps the experts disagree, but most of those with big reputations line up behind $P$ and for present purposes that's good enough for you to go with $P$. Or perhaps there is some general reason to question $S$ 's reliability (e.g., $S$ is getting paid for her opinion), yet on this occasion there is also reason to think that $S$ 's integrity with respect to $P$ is not in any doubt. It's a judgement call, and no set of conditions specifying all the factors and how to weight them that applies in all cases can usefully be set out.

Yet another variable that prevents formulating complete checklists is that the degree of confidence in the position that is needed will vary. When life-ordeath information is needed, then confidence approaching certainty is desireable in a source. When convenience is important, and it doesn't matter much whether the position is slightly wrong, then it might be perfectly adequate to accept a $P$ in an area of specialized knowledge on the advice of an $S$ who is only slightly more knowledgeable than oneself.

A final complication is that, even assuming no conflict between the plausibility of $P$ and the credibility of $S$, the various factors can conflict in particular situations in which judgement about $P$ is required. Perhaps a life-ordeath decision must be made, which calls for certainty, but one has only a few minutes in which to make it (as can happen in hospital emergency wards), which calls for a quick-and-dirty judgement. The need for practicality and the need for certainty conflict in such cases, and that affects the conditions of reasonable reliance on a source in those situations. A different kind of example: perhaps most authorities agree that $P$, yet one eminent authority, who has a track-record for astute, minority judgements, dissents.

\subsubsection{Generalizations from the first example}

We have seen that in the case of reasoning to the truth of information on the basis of the sayso of some source it gains its rationality from the social practice of truthfulness. This practice at the same time justifies our reliance on sources for information, and alerts us to various limits on that reliance. Our recognition of those limits inspires a check-list of the common sorts of excepting circumstances. If this case is at all typical, we can in general expect to find some such particular ground for relying on the reasoning pattern captured by any reasoning scheme. As well, we should not expect that reliance to be justified unconditionally. For any given reasoning scheme there will be 
exceptions, and to the extent that the exceptions can be classified, we can generate a check-list of critical questions to guide anyone using the reasoning scheme in question.

We have also seen that, for a number of reasons, it is not possible to provide a single, simple, universally applicable list of specific critical questions for a reasoning scheme. The attempt to provide a complete set of specialized sets of critical questions for each type of occasion in which a scheme might be used, while it might be interesting, would result in a welter of question-sets, with unavoidably problematic splitting of closely related by slightly different contexts, and much overlapping. The result would have dubious practical value. Thus, the criterion of selection for critical questions is their usefulness for the purpose at hand. Accordingly, not only is there room for reasonable disagreement about any given set of critical questions, given that means-ends judgements are in principle contestable, but also there may be different sets of critical questions for any given reasoning scheme, each for its own purpose.

In other words, the critical questions associated with a reasoning scheme are generated by knowledge of the types of circumstances in which there are exceptions to what is normally good reasoning. What makes the reasoning good in the normal or default situation is what might be called the warranting condition of that kind of reasoning. In the case of reasoning based on information provided by a source, the proposal made here is that the warranting condition is the existence of the social practice of truthfulness. That is what justifies the reasoning. In some loose sense of entailment, we might say that the the practice of truthfulness entails $P$ for $R$ in $C$ when $S$ tells $R$ that $P$ in $C$, other things being equal. We will see that the warranting condition is what justifies the warrant that functions in the reasoning scheme.

The suggestion is that the rationality of reasoning schemes is a local, or individual matter. Each normative scheme will have its own warranting condition. (Thus "different" schemes that have the same warranting condition should turn out to be varieties of the same generic scheme.) This contention can only be justified inductively, but the discussion of the scheme for reasoning from information from a source is a start. In order to strengthen the case, I will next show how these generalizations apply to some other reasoning schemes.

\subsubsection{Another example: reasoning from a priori analogy}

When reasoning from analogy is good reasoning, why is it good reasoning? We quickly notice that there is both normative and empirical reasoning from analogy: sometimes we draw conclusions about what is right or wrong, what ought or ought not to be done, what is good or bad, or how something ought to be understood, on the basis of analogies, and sometimes we draw conclusions about what is probably in fact the case on the basis of analogies (and in the latter case, sometimes our conclusions are general and sometimes they are particular). Consider for present purposes only the first kind of case, labelled by Govier a priori reasoning from analogy. 
One convicted sexual offender gets a four-year jail sentence, another gets a one year jail sentence. It is argued that the penalty of the second is unjust, or that the penality of at least one of them is unjust. The reason given for the complaint of injustice is that both offenders were convicted of the same crime, and the nature of their respective offences was similar. Was the judge in the second case wrong-was his reasoning bad? The judge in the second case says that the sentence is lighter than usual because the second offender, unlike the first, is very old and ill. Presumably the judge is reasoning that the effect of the punishment on the offender should be similar in similar cases, and that the effect of a one-year sentence on the aged and ill offender will be similar to the effect of a four-year sentence on a younger offender. Was the judge in the second case right-was his reasoning good after all?

What seems to underly a priori analogical reasoning is the principle that similar cases should be treated, or conceived, similarly, or in other words, the assumption of the rationality of consistency. If two cases are similar in the respects relevant to the kind of judgement being made about them, and there are no particular reasons in the circumstances for distinguishing them, then to make a particular judgement of one but not the other is inconsistent or arbitrary. What counts as consistent treatment is a judgement call, given realworld complexities such as the differences between the convicted offenders in the kind of case alluded to above. Moreover consistency is not the only value there is, so whether it should be overridden in a particular case is also a judgement call. Still, consistency is an avatar of rationality, and reasoning based on it is prima facie good reasoning. We might call consistency the "warranting condition" of a priori reasoning from analogy.

\subsubsection{Additional examples}

It should be possible, if the thesis being developed here is true, to supply the warranting condition for any reasoning scheme that has substitution instances that count as good reasoning. Walton (1996) lists twenty-five of what he terms "the" argument schemes. Although there are problems with his formulations (for example, some are entailments, as stated) Walton's list provides a good sample for testing our thesis. But rather than discuss all twenty-five schemes in detail, one by one, it will be more efficient to comment briefly on the generic warranting conditions that recur in the reasoning schemes that Walton describes.

One of these warranting conditions might be called the implication of a convention or practice, and it is found in Walton's schemes labelled "argument from a position to know" and "argument from expert opinion." Both of these are special cases of reasoning from information provided by a source, and we have already discussed how that scheme relies on the convention of truthfulness. The general idea is that, given the existence of a certain social convention or practice, one is justified in normally expecting conduct of a certain sort when that practice is in play, for that is what it means for the practice to be operative. 
A second generic warranting condition is consistency. For example, in Walton's "argument from commitment"-reasoning that someone should do something by virtue of some commitment they have made-the appeal seems to be to acting in a way that is consistent with that commitment. (Or, perhaps the argument from commitment is another case of relying on a social convention, that of promising. One could also see classify this reasoning as employing a sort of ceteris paribus class or quantificational logic, for it takes the following form: "All those who have a committment to $X$ should, ceteris paribus, do A; you have made a commitment to X; so you should do A.") A special case of the argument from commitment is the "argument from established rule," since it appeals to a rule to justify a judgement, and such an appeal has force only if the person to whom the judgement applies has a commitment to following or obeying that rule in general. The "argument from verbal classification"-for example, one of my late father's standard rejoinders, "That policy is unacceptable: it's pure socialism!"-seems similarly to employ consistency as its warranting condition: consistency with the classification in question implies assigning the property mentioned. And it too can be modelled by a kind of ceteris paribus class or quantificational logic: "This A may be classified as an X, X's normally have property Z, so this A has property Z." Walton's "argument from consequences" scheme is a kind of causal-cumnormative reductio ad absurdum reasoning. The reasoning is that a given act or policy will have bad consequences and so shouldn't be done or implemented. The consequence is not a logical one but a causal one, and its "absurdity" consists not of contradiction, but of undesireableness. But again, what warrants the reasoning is an appeal to consistency, this time between espoused values and the consequences of actions. A special case of the argument from consequences scheme is the "argument from causal slippery slope." This is the reasoning that taking a first step will cause a second, which will cause a third, and so on until a final consequence that is undesirable is reached, and therefore refraining from taking the first step is justified. Another special case of the appeal to consequences reasoning is what Walton labels the "argument from waste," which is the reasoning that because a large investment towards reaching an uncertain outcome has been made to date, and because that investment would be wasted if the efforts were broken off, the pursuit of that outcome should be continued. In both the causal slippery slope argument and the argument from waste the appeal is to act consistently with (the implications of) one's values.

Another of Walton's schemes belonging to the group relying on consistency as the warranting rationale is reasoning from analogy, discussed in detail above. Reasoning from analogy is itself a generic reasoning scheme. The "argument from precedent" and its variant, the "precedent slippery slope argument" both appeal to analogies in their reasoning and so too rely on consistency as their warranting condition.

A category of reasoning schemes that appeals to consistency in another way takes the form of reasoning to an explanation. Both Walton's "argument from evidence to a hypothesis" and "argument from a correlation to a cause" 
have this feature. When we reason in these ways we are seeking order in the world we experience-either to find it or to impose it. Why? Maybe there is order that manifests itself to us. Maybe there is some survival instinct that causes us to construct an order, since order permits predictions. These are deep and difficult questions, but whatever their answers, the orderseeking/finding of this reasoning is undeniable, and what we seek is an account that is consistent with both the new data and what we already believe.

A half-dozen of Walton's reasoning schemes rely in one way or another on spelling out the causal implications of causal generalizations in particular circumstances. The "argument from cause to effect" is the generic scheme of this group.The warrant of such reasoning is a causal generalization, and the warranting condition is the nature of causality as we understand it. Given that events of type A cause events of type B, the occurrence of a particular A justifies inferring the occurrence of a particular B, ceteris paribus. The "argument from sign" might be called the argument from effect to cause. It is reasoning from something that is a sign of a thing to the presence of the thing itself, and assumes a causal relation between the sign and the thing signified. Walton's example-there are bear tracks, so there's a bear-assumes (safely enough) that bears normally are the cause of bear tracks. The "circumstantial argument against the person" is a variation, for it involves reasoning from a generalization that one type of property (say, inconsistency between preaching and practice) is causally associated with another (say, the unreliability of what's preached). The "argument from popularity" is reasoning from the fact that a position is widely held to the conclusion that it is plausible. This would appear to be a special case of reasoning from a source, with the credibility of the source being taken to lie not in an individual's trustworthiness or expertise, but in the strength of numbers. However, it is more likely that underlying this reasoning is the assumption of a causal relation between a position's being widely accepted and its being true, ceteris paribus - the assumption that error would not survive the scrutiny of so many. The "ethotic argument," that someone's good character is vouchsafe for the truth of her pronouncements, relies on assuming a general causal relation between character and credibility. The "argument from bias" is one inverse of the ethotic argument, involving as it does reasoning that bias undermines crediblity, thus relying similarly on a general causal claim. All of these variaties of inferring a particular causal implication of a general causal claim share the general assumption of the rationality of our causal understanding.

I have left to the end a couple of examples that seem to rely on an analogue of the logical principle of modus tollens exported to the non-deductive world. What Walton calls the "argument from vagueness of verbal classification" is reasoning that because a verbal classification is too vague, no particular application of it can be made. One of his examples is the argument that the point at which a fetus becomes a human person cannot be used as the dividing line between permissible and impermissible abortion, because that "point" is too vague. In general the reasoning seems to be that for a judgement or decision to rely on a degree of precision, such precision must be possible; 
but in the given case such precision is not possible; so the judgement or decision cannot rely on that kind of precision in the given case. Walton's "argument from arbitrariness of a verbal classification" is similar. For a judgement to rely on a non-arbitrary verbal classification, such non-arbitrary classifications must be possible, but in the given case such a non-arbitrary classificiation is not possible, so in the given case such the judgement cannot rely on such a classification. Both of these are cases of qualified modus tollens reasoning (if $p$ then $q$; but not $q$; so not $p$ )—qualified, because unlike modus tollens proper, each of them includes a ceteris paribus clause. The warranting condition of these reasoning schemes is the rationality of the idealized entailment.

So much for the abbreviated treatment of Walton's particular argumentation schemes, most of which have been discussed. Admittedly the argument is sketchy, but what it suggests is that there is a relatively small number of types of rationale for reasoning in these various ways, which may or may not reduce to one or another aspect of consistency, but which really do justify such reasoning when all things are equal, but which don't justify it universally, since frequently other things are not equal and so an exception must be made.

\subsubsection{Recapitulation}

We can now see what Hastings meant by calling schemes "modes of reasoning." More precisely, a reasoning scheme represents a particular way or manner of reasoning. We can see what Walton meant by describing them as structures of argument (we would say, of "reasoning"). A reasoning scheme sets out the pattern that is instantiated in particular substitution instances of reasoning or argument. We can see why Kienpointner takes the Toulmin model to capture the prototype or most general type of structure of a reasoning warrant. Each of these modes of reasoning is distinguished by the ceteris paribus (Walton's "pragmatic") principle that authorizes or warrants inferring a particular conclusion from a particular configuration of grounds or evidence. (There is no objection to including the warrant as a component of the scheme that parallels the objection to including the associated conditional of an argument as a premise in the reconstructed argument-that it opens the door to a vicious infinite regress. For a scheme is not an argument or an argument form, and the warrant is not an associated conditional.) The warrant of a scheme derives from the particular conditions or features that make an inference of that type rational, when there are no circumstances that require making an exception and cancelling the default. And finally, we can see why van Eemeren and Grootendorst focussed on a very small number (three) of "categories" of schemes, while acknowledging that "[o]f course, there are many subcategories of argumentation schemes" (1992: 97). Walton's list of 25 turned out to contain a quite small number of subsets, each of which could be distinguished by being a variation of a single general warranting principle. And van Eemeren and Grootendorst are also right to use the evaluative function of reasoning schemes as their principle of classification: "Each type of argumentation corresponds to certain assessment criteria that pertain to the 
relation represented in the argumentation scheme" (1992: 98). This is another way of using the warrants used in reasoning schemes as the basis of their classification, and recognizes the central role of these inference licenses in the conception of a reasoning scheme.

Not everything in these three accounts should find its way into in a general theory of reasoning schemes.

Van Eemeren and Grootendorst's "category" of reasoning that something is symptomatic of something else is itself a special case of applying a causal generalization (as we saw above in discussing Walton's "argument from a sign"), and so is not as general a category as they take it to be. Also, there appear to be more than three basic categories of reasoning schemes (though, to be fair, van Emeren and Grootendorst do not explicitly claim there are only the three they describe).

Walton's qualification that this sort of reasoning is "provisional" and "inherently tentative" (1996: xi, 42) conflates defeasability with insecurity. Given that none of the excepting conditions applies, a presumption in favour of a position can be so secure that it would be irrational to deny the position. If you make a promise, then if no excepting conditions apply, you ought to keep your promise —not provisionally, or tentatively, but most definitely—all the while acknowledging that there might be some factor you have overlooked, or some new factor that will change the picture. The falsifiability of scientific claims does not prevent us from being (with justification) morally certain about some of them, and the defeasibility of the conclusions of reasoning using schemes similarly justifies moral certainty about them, when the appropriate conditions are met.

One of Walton's chapter titles, "The Argumentation Schemes" (1996: 46), conveys the unfortunate suggestion that there is a definite number of reasoning schemes. We have seen that this cannot be so, since it is possible to parse reasoning at various levels of generality, and the specification, and count, of reasoning schemes will vary accordingly.

\subsection{The general theory of reasoning schemes}

A complete account of reasoning schemes has to solve a number of problems. One is the individuation problem: what consitutes a single scheme? When there is a long sequence of reasoning, or a complicated argument, are there many schemes linked together, or just one scheme? Can there be more and less complex schemes, or simple and compound or single and multiple schemes? A second is the identification problem: what determines whether a scheme is the correct scheme of a reason? A third is the classification problem: how many schemes are there and how are they related to one another? A fourth is the evaluation problem: how is it decided that the reason that instantiates a given scheme is cogent?

The account above has already supplied solutions to the classification and 
the evaluation problems. Systems of classification are relative to their purposes. Consequently, there can be no "correct" typology of reasoning schemes. The only pertinent question is whether any particular classification successfully or optimally fulfills its purpose. And what makes an instantiation of a given scheme cogent is that the warrant of the reasoning is rational and none of the excepting conditions applies in that case. We have seen that there is no single or universal principle of rationality for such reasoning, that the warranting conditions apply only for the most part or ceteris paribus, and we have also seen that the excepting conditions are highly context sensitive. In the remainder of the paper I take up the individuation and the identification problems.

\subsubsection{The individuation problem: howmany?}

What is the scope of a reasoning scheme? In the literature on schemes the focus has been on small units. Kienpointner's prototype includes a set of data (which presumably can be expressed by a set consisting of more than one sentence) and a warrant that authorizes the drawing of a single conclusion or "claim" directly from that data set. Walton's examples contain a small number of premises (or premise types) which together are supposed to provide direct presumptive support for a conclusion (or conclusion type). Here is an example, a slight modification of Walton's account of the (scheme of the) "argument from popular practice" (1996: 84):

If a large majority (everyone, or nearly everyone, etc.) does $A$, or acts as though $A$ is the right (or an acceptable) thing to do, then there is a presumption that $A$ is a prudent course of action.

A large majority acts as though $A$ is the right thing to do.

Therefore, $A$ is a prudent course of action.

By defining schemes as reasonining schemes, and by defining a reason as a unit of support for a position, we solve the invidividuation problem in short order. A scheme will be the scheme of a reason, and a reason is the smallest self-standing unit of support for a position. Thus, what are in Freeman's (and others') terminology, "convergent" and "serial" arguments will necessarily exhibit two or more reasoning schemes (1991: Ch. 8). In the case of a convergent argument, each branch of argument supporting the conclusion will instantiate (be a substitution instance of) a separate token of a scheme (although they could, coincidentally, all happen to be instantiations or tokens of a single scheme-all arguments from analogy, for example); and in the case of a serial argument, each step in the chain of arguments will instantiate a separate token of a scheme (again, possibly tokens of the same scheme). In terms of Snoeck Henkeman's (1992) analysis of both cumulative and complementary arguments, there will be more than one scheme at work. She takes each "premise" in such arguments to represent a reason for a different 
claim. For example, for the argument that might be stated:

I think she's in love with him because she blushes every time he starts speaking to her and she also keeps talking about him.

she takes the correct analysis to be as follows [I have supplied the numbering] (1992: 96):
A [arguer] (1) I think she's in love with him.
B [actual or anticipated audience] (2) Why do you thinks so?

A (3) She blushes every time he starts speaking to her.

B (4) Well, that doesn't necessarily mean that she's in love with him.

A (5) No, but she also keeps talking about him.

In the present terminology, A offers (3) as a reason for (1), and subsequently A offers (5) as a reason for (1). So there are two schemes in play here, possibly both of the same type.

Freeman (1991: Ch. 8) makes a good case for counting convergent and serial arguments as single arguments, and his reasoning would apply equally to what Snoeck Henkemans calls cumulative and complementary arguments. If Freeman is right, a single argument may exhibit several schemes. His point gives us another reason for identifying schemes with reasons and not with arguments.

\subsubsection{The identification problem: which one?}

A scheme can be more or less abstract, depending on how much of the statement of the reasoning or the argument that it represents is expressed by variables and on how large are the units of the argument expressed by a single variable. Thus one reason can be expressed by more than one variation of a scheme, the variations being a function of the variations in their type or degree of abstraction from the reason.

In the literature, sometimes actual reasoning or an argument is quoted and a scheme is formulated that is purported to be the scheme of that reasoning or argument. Let us call such schemes "descriptive," since they are purported to describe accurately the patterns of particular reasons people have actually used or might use. The reasons so portrayed may or may not in fact be cogent, so there can be correct descriptive schemes of bad or fallacious reasoning or arguments. Such schemes are "correct" just in case they accurately portray the pattern of the reasons in question. Sometimes in the literature schemes are formulated and proposed as patterns of cogent reasoning or argument. Let us call such schemes "cogent" just in case they portray patterns of reasons which can have instantiations that are cogent. It might be debatable whether a 
particular scheme is in fact cogent in this sense. A particular scheme may be both descriptive and cogent; that is, it may accurately capture the pattern of a particular reason, and such a reason might also be cogent. The identification problem applies to descriptive schemes; the question of whether a scheme is cogent constitutes the evaluation problem.

By the way, to forestall a possible confusion, it is important to distinguish between the type of scheme and the type of reasoning or argument. Let us call an instance of reasoning or argument "empirical" if its conclusion is an empirical, factual or descriptive sentence or proposition, and let us call it "normative" if its conclusion is a presciption or a commendation. Any argument of either type will exhibit at least one descriptive scheme, and presumably there can be cogent schemes for reasoning or arguments of both types. This distinction corresponds to Kienpointner's distinction between schemes for "deskriptive Propositionen" and "normative Propositionen" (1992: 166, but also passim).

There are often several possible formulations of the scheme of a particular episode of reasoning. For example, the following reasoning might be represented by any one of the schemes listed below it:

I guess my car keys are in the pocket of my coat in the closet at home because I don't have them with me and I think that's the only other place they could be.

(S1) If an object is probably located in the pocket of my coat in the closet at home or on my person, and it is not in one, it is probably in the other.

Object $\mathrm{X}$ is located either in that coat pocket or on my person.

Object $\mathrm{X}$ is not on my person

So,

Object $\mathrm{X}$ is probably in the pocket of my coat in the closet at home.

(S2) If an object is probably located in location $A$ or in $B$, and it is not in one, it is probably in the other.

Object $X$ is located either in location $A$ or in location $B$.

Object $X$ is not in location $A$.

So,

Object $X$ is probably in location $B$.

(S3) If an object probably has property or property, then if it does not have one, it probably has the other. 
Object $X$ has property $A$ or property $B$.

Object $X$ does not have property $A$.

So,

Object $X$ probably has property $B$

(S4) (disjunctive syllogism)

Either $p$ or $q$.

Not $p$.

So,

$q$

We can think of schemes as reason-types, and substitution instances of schemes as reason tokens. What counts as the correct schematic interpretation of a reason token may be a matter of debate. Any token of reasoning or argument will represent at least one descriptive scheme, but whether a particular descriptive scheme accurately portrays a given reason token may be debatable. On what grounds are such disagreements to be settled?

Consider an example. Walton (1996: 83) gives an example of what he calls the argument from popularity:

Nearly everyone who lives in Cedar Rapids thinks that the lake is a good place to swim in the summer. Therefore, the lake in Cedar Rapids is probably (plausibly) a good place to swim in the summer.

And he offers the following as the "argumentation scheme" for the argument from popularity (ibid.):

If a large majority (everyone, nearly everyone, etc.) accept $A$ as true, than there exists a (defeasable ) presumption in favour of $A$.

A large majority accept $A$ as true.

Therefore, there exists a presumption in favour of $A$.

"This kind of argumentation," Walton says, "is deductively invalid, and generally it is not highly reliable" (ibid.). But as Walton has formulated it, any substitution instance of this scheme will be deductively valid, for it will have the form of modus ponens. Since Walton is here interested in schemes for presumptive reasoning, which he understands explicitly as not deductive reasoning, it looks as though his formulation of the scheme for "argument from 
popularity" is a slip-up—not what he intended. The scheme for the reasoning used in this type of argument must reflect the type of reasoning it is, or may most plausibly be taken to be. We might try the following:

(1) If everyone or nearly everyone who has an opinion about it believes $p$ is true, then there is a presumption in favour of $p$ 's being true, and (2) just about everyone who has an opinion about it does believe $p$ to be true.

So, in the absence of reasons to the contrary,

(3) $p$ may be taken to be true.

In this formulation, substitution instances of (1) and (2) do not entail the corresponding substitution instance of (3).

If we may generalize from this example, one constraint on, or rule for, the formulation of a descriptive reasoning scheme would be that it should accurately represent the kind of reasoning that it purports to be. To be sure, it is not always possible to know what kind of reasoning the reasoner or arguer intended, and in situations in which that intent cannot be determined there is no way to decide with certainty what the correct formulation of the descriptive reasoning scheme is. At this point general principles of interpretation such as Charity must be applied.

We can use Walton's example to illustrate another constraint or rule. Suppose someone offered the following as the reasoning scheme of Walton's Cedar Rapids example of an argument from popularity.

If $p$, then presumptively $q$.

p.

So, presumptively,

q.

In this case, the problem is that by supplying a variable for the entire antecedent, the proposed scheme (qualified modus ponens) abstracts too much, removing from view properties of the reasoning that are essential to its particular nature. It is like an arial photograph taken from too high up, or without sufficient resolution, to reveal the topographical features of interest to its viewers. We can thus make a rule that a scheme must exhibit the particular warrant of the reasoning: the properties of the reasoning that are salient to its (alleged) cogency. The implication is not, by the way, that modus ponens is never the appropriate focus; the point is that it fails to exhibit perspicuously the warrant of the reasoning employed in the argument from popularity.

It may be that it is a tacit recognition of this rule-a concern with exhibiting the feature of the reasoning salient to its cogency-that leads Kienpointner 
(1992: 19ff.) to adopt the Toulmin model as the "prototype" of all argument schemes. In the Toulmin model, the "warrant" is the statement of the "principle" by virtue of which the "backing" information may be taken as support for the "claim" (Toulmin, 1958). Thus the warrant makes explicit why the inference of the claim from the backing is supposedly justified. (In my terminology, both "backing" and "warrant" are parts of a reason for a position.)

To sum up, a descriptive scheme of an instance of reasoning should satisfy at least two requirements:

(a) the scheme should accurately represent the kind of reasoning intended by the reasoner or arguer;

(b) the scheme should perspicuously exhibit the features of the reasoning that are salient to its (alleged) cogency.

\section{CONCLUSION}

If the argument of this paper is correct, the theory of normative reasoning schemes constitutes at least one part of the theory of probative reasoningreasoning the inferences of which are neither deductively valid nor quantitatively inductively strong, yet which, nonetheless, can be cogent. Normative reasoning schemes capture the structure of such reasoning, including its warrants, and thereby display how such inferences are rational, even though they are not logical entailments and not scientific inductions. This rationality is not left to "intuition," but in each case can be traced to a particular way in which rationality is manifest. The application of normative reasoning schemes requires an understanding of these local manifestations of rationality, often in considerable specific detail. For such rationality is highly contextual, and the conditions of its exercise are accordingly specific to those contexts. These conditions are monitored by the so-called critical questions that theorists have associated with reasoning schemes, and these critical questions thus play an integral role in the application of these schemes.

To the extent that the informal fallacies are associated with normative reasoning schemes, as Walton (1996) makes a plausible case that they are, we can understand how the study of fallacies has occupied such a central role in informal logic scholarship. Walton argues that the informal fallacies are essentially related to abuses or improper uses of reasoning schemes in reasoning or argument. But reasoning schemes supply the rationale for the Third Category of reasoning and argument, and the field of informal logic is centrally concerned to understand the rationale of non-formal reasoning-more precisely, reasoning the inferences of which are not deductive entailments. Hence it is entirely appropriate that the attempt to understand informal fallacies has been a preoccupation of informal logic.

If this paper is on the right track, it does not bring an end to the inquiry, but rather opens the door to further work. The specific rationales of particular types of reasoning scheme have been scarcely more than suggested, and in each 
case require much more thorough investigation. If the suggested general rationale for critical questions is correct, then it is likely that it will be possible and useful to work out a heuristic for the formulation of critical questions. The pedagogy of reasoning schemes also would need to be addressed, since some simplifications might be needed for teaching purposes, especially at the introductory level. The tasks of producing elegant and perspicuous formulations of the most commonly used reasoning schemes and of giving a correct account of the different types of generic schemes remain to be taken up. And last but not least, the theoretical question of whether so-called inductive reasoning is sui generis, or whether it should be considered to constitute another family of presumptive reasoning schemes, is worth considering. It might turn out that there are not three broad Categories of reasoning, but just two after all: not deductive and inductive, but deductive and non-deductive, with inductive or empirical reasoning being one sub-class of the latter.

\section{ENDNOTES}

1 I use 'valid' and 'entail' in the way they are widely used in textbooks in formal, symbolic or deductive logic. See Copi's account of validity (1967: 20-21); Kalish and Montague's characterization of a valid argument (1964: 14); Leblanc and Wisdom's account of entailment (1976: 5); Georgakarakos and Smith's account of entailment (1979: 9-11); Carney and Scheer's definition of 'valid argument' (1980: 12); Lambert and Ulrich's definition of a 'valid argument' (1980: 16); Jeffrey's definition of 'valid inference'(1981: 1).

2See Lambert and Ulrich (1980: 4) for a typical expression of the prevailing view: "If a piece of reasoning is not deductive, but nevertheless intended to provide some evidence for the conclusion, then it is said to be inductive reasoning, and the argument that represents it is an inductive argument." See also Skyrms (1966).

$\underline{3}$ In referring to Kienpointner, I must make a confession. His 1992 book, Alltagslogik, Struktur und Funktion von Argumentationsmustern, has as yet not been translated into English, and my reading knowledge of German is woefully deficient. So I have not been able to read more than bits of this book, and it may be that Kienpointer has anticipated many or all of the points made in this paper. My only excuse for forging ahead without taking the time to master German sufficiently to read Kienpointner's book is that these points have not yet been adequately addressed in English, and if my account simply repeats points Kienpointer has already made, well, perhaps that gives them a degree of independent confirmation. 
Carney, James D. \& Scheer, Richard K. (1980.) Fundamentals of Logic. $3^{\text {rd }}$ edition. New York: Macmillan Publishing Co., Inc. and London: Collier Macmillan Publishers.

Copi, Irving M. (1967.) Symbolic Logic. $3^{\text {rd }}$ edition. New York: Macmillan Publishing Co., Inc. and London: Collier Macmillan Publishers.

Eemeren, Frans H. van \& Grootendorst, Rob. (1984.) Speech Acts in Argumentative Discussions. Dordrecht: Foris.

Eemeren, Frans H. van \& Grootendorst, Rob. (1992.) Argumentation, Communication and Fallacies. Hillsdale, NJ: Lawrence Erlbaum Associates.

Feldman, Richard. (1999.) Reason and Argument. Upper Saddle River, NJ:

Prentice-Hall. $2^{\text {nd }}$ edition ( $1^{\text {st }}$ edition 1993).

Freeman, James B. (1991.) Dialectics and the Macrostructure of Argument. Amsterdam: Mouton de Gruyter.

Georgacarakos, G.N. and Smith, Robin. (1979.) Elementary Formal Logic. New York: The McGraw-Hill Book Company.

Govier, Trudy. (1980a.) Review of Challenge and Response by Carl Wellman. Informal Logic Newsletter 2: 10-15.

Govier, Trudy. (1980b.) "Assessing Arguments: What Range of Standards?" Informal Logic Newsletter 3: 2-4.

Govier, Trudy. (1987.) Problems in Argument Analysis and Evaluation. Dordrecht: Foris Publications.

Govier, Trudy. (1999.) The Philosophy of Argument. Newport News, VA: Vale Press.

Groarke, Leo. (1999). "Deductivism Within Pragma-Dialectics."

Argumentation 13: 1-16.

Groarke, Leo, Tindale, Christopher W., Fisher, Linda. (1997.) Good Reasoning Matters! $2^{\text {nd }}$ edition. $\left(1^{\text {st }}\right.$ edition, by Frederick Little, Groarke and Tindale, 1989.) Toronto: University of Toronto Press.

Harman, Gilbert. (1986.) Change in View, Principles of Reasoning. Cambridge, MA: MIT Press (Bradford).

Hastings, A. (1963.) A Reformulation of the Modes of Reasoning in Argumentation.. Ph.D. dissertation. Northwestern University, Evanston, Illinois.

Jeffrey, Richard. (1981.) Formal Logic: Its Scope and Limits. $2^{\text {nd }}$ edition. New 
York: McGraw-Hill Book Company.

Johnson, Ralph H. and Blair, J. Anthony. (1977.) Logical Self-Defense.

Toronto: McGraw-Hill Ryerson. $3^{\text {rd }}$ edition, 1993. (First United States edition, New York: McGraw-Hill, 1994).

Kalish, Donald \& Montague, Richard. (1964.) Logic, Techniques of Formal Reasoning. New York: Harcourt, Brace \& World, Inc.

Kienpointner, Manfred. (1992.) Alltagslogik, Struktur und Funktion von Argumentationsmustern. Stuttggart-Bad Cannstatt: frommann-holzboog.

Lambert, Karel \& Ulrich, William. (1980.) The Nature of Argument. New York: Macmillan Publishing Co., Inc. and London: Collier Macmillan Publishers.

Leblanc, Hughes \& Wisdom, William A. (1976.) Deductive Logic. $2^{\text {nd }}$ edition. Boston: Allyn and Bacon, Inc.

Mill, John Stuart. (1861.) Utilitarianism. (Reference is to the Hackett edition, 1979, ed. and intr. by George Sher.)

Mowatt, Farley. (1951.) People of the Deer. Toronto: McClelland and Stewart.

O'Keefe, Daniel J. (1977.) "Two Concepts of Argument." Journal of the American Forensic Association 13: 121-128.

O'Keefe, Daniel J. (1982.) "The Concepts of Argument and Arguing," in J. Robert Cox and Charles A. Willard Eds.), Advances in Argumentation Theory and Research. Carbondale: Southern Illinois University Press, 3-23.

Pinto, Robert C. (1995.) "The Relation of Argument to Inference." In Frans H. van Eemeren, Rob Grootendorst, J. Anthony Blair, Charles A. Willard (Eds.), Proceedings of the Third ISSA Conference on Argumentation, Vol. I, Perspectives and Approaches. Amsterdam: SicSat, 271-286.

Reiter, R. (1987.) "Non-monotonic Reasoning." Annual Reviewof Computer Science, 2: 147-186.

Scriven, Michael. (1976.) Reasoning. New York: McGraw-Hill.

Scriven, Michael. (1987.) "Probative Logic: Review and Preview." In Frans H. van Eemeren, Rob Grootendorst, J. Anthony Blair and Charles A. Willard (Eds.), Argumentation: Across the Lines of Discipline. Dordrecht/Providence: Foris Publications, 7-32.

Snoeck Henkemans, A.F. (1992.) Analysing Complex Argumentation. Amsterdam: SicSat.

Skyrms, Brian. (1966.) Choice and Chance. Belmont, CA: Dickenson 


\section{Publishing Co.}

Toulmin, Stephen E. (1958.) The Uses of Argument. Cambridge: Cambridge University Press.

Walton, Douglas N. (1996.) Argumentation Schemes for Presumptive Reasoning. Mahwah, $\mathrm{NJ}$ : Lawrence Erlbaum Associates. 